\title{
Teaching Design and Application of Electromechanical Comprehensive Experimental Course
}

\author{
Yanying Wang \\ The academic of produce Engineering \\ Dalian University \\ Dalian City, Liaoning, China
}

\begin{abstract}
Practice teaching is an important part of electromechanical courses. Many electromechanical courses including practical links can't do without the support of the laboratory. Due to the limitation of time and space, only some students can improve their practical ability. For improving this situation, the mechanical manufacturing professional of college took measures to do comprehensive teaching design on the electromechanical experimental course based on years of teaching reform and exploration. These measures included the virtual simulation experimental teaching, the micro-course with the project as the unit and the latest assessment method by using software Camtasia to record the screen. After several rounds of practice and improvement, electromechanical experimental courses had been deeply loved by students. Moreover, the students' practical ability and innovation ability have been improved.
\end{abstract}

Keywords-Virtual simulation experiment; Micro-course; Record the screen

\section{INTRODUCTION}

The college has many electromechanical courses including practical links, such as electromechanical transmission, electromechanical comprehensive experiment, hydraulic transmission, and electromechanical direction comprehensive practice. All of them contain a large number of experimental links. By integrating the experimental teaching contents of electromechanical courses, giving full play to the advantages of subject groups and sharing experimental resources, students' basic experimental skills can be improved and their abilities of comprehensive analysis and problem-solving can be cultivated. Traditional electromechanical experiments can't do without the support of the laboratory. To be limited by time and space, only some students can improve their practical ability in the laboratory. The virtual simulation experiment and the microcourse based on the project can provide an effective way for the experimental teaching of electromechanical courses and can solve the above problems well [1].

\section{CURRENT SITUATION ANALYSIS}

A. Experimental courses are limited by time and space, and it is difficult to make great improvement

Due to the long construction period of the laboratory and the limited experimental equipment, it happened that more than one student Shared one equipment for practice. In addition, students generally had less time and more homework, and they frequently switched between several experimental courses during the teaching period, thus resulted in poor teaching effect. The virtual simulation experiment of network teaching can make full use of students' fragmented time to digest and replace part of the experiment [2-3].

\section{B. The low degree of integration of course modules affects the effect of experimental teaching}

The single experimental course is making the complete teaching knowledge system fragmented, making the experiment of each course become isolated teaching, and lacking the internal connection between disciplines. So, the students were difficult to integrate the fragmentary experimental content.

\section{Single teaching means is not conducive to stimulate students' interest in learning}

The current courses usually matched experiment projects with verification type and demonstration type, so they still belonged to the traditional experimental teaching. Experimental teaching with fewer credit hours can only make students passively complete the verification of theoretical knowledge, but it was difficult to improve their practical ability and innovation ability.

\section{The high cost of experimental teaching}

With the rapid development of mechanical and electrical products, university laboratories also need to keep up with the development of science and technology. For it, many universities bought new equipment and a new system. These increased the experimental teaching cost. In addition, the electromechanical experimental courses involve disassembly, obstacle removal, and verification and so on. The consumables 


\section{VIRTUAL SIMULATION CONTROL OF POSITIVE AND NEGATIVE ROTATION OF THREE-PHASE ASYNCHRONOUS MOTOR WITH DOUBLE INTERLOCK} that the real experiment does not have or is difficult to complete. For the high cost, high consumption, large or comprehensive training, it can also provide reliable, safe and economic simulation projects.

\section{E. Single performance evaluation standard affects the effect of experimental teaching}

For traditional experimental projects, the final performance evaluation was mainly based on the actual laboratory performance, operational habits and the preview, writing and completion of experimental reports. The final evaluation for students was difficult to do distinguish due to the standard was single and fuzzy. So, report writing just became a form.

\section{TEACHING DESIGN}

It is mainly composed of two parts: virtual simulation project of mechanical and electrical comprehensive experimental course and modular integration of the multicourse experimental project.

\section{A. Project-based virtual simulation of experimental courses}

Some typical experimental projects were extracted from electromechanical comprehensive courses. Based on the virtual simulation experimental platform, typical virtual simulation experimental projects were constructed to improve the projectbased teaching. The typical projects were extracted from the two courses were as follows:

- Electromechanical drive and control course: three-phase asynchronous motor positive and negative rotation control, table automatic round-trip cycle control, threephase asynchronous motor sequence control;

- Mechanical and electrical comprehensive experiment courses: traffic lights PLC control, four-floor elevator PLC control, PLC water tower water level automatic control.

\section{B. Integration modular of multi-course experimental projects}

The course extracted the common international simulation modularly:

- Integration of hydraulic and pneumatic transmission in electromechanical transmission control: hydraulic power head control simulation module, automatic tool rest electro-hydraulic control simulation module

- Integration of hydraulic transmission and electromechanical transmission control: hydraulic pump simulation module, typical hydraulic circuit experimentsimulation module of the two-position four-way electromagnetic reversing valve

- Integration with electromechanical drive control in the electromechanical comprehensive experiment: CA650 horizontal lathe electrical control circuit simulation module
A. Positive and negative rotation control principle of a threephase asynchronous motor with double interlock

Double interlock was the normally closed contacts of the positive and negative start buttons that are connected in series with each other in the control loop, and the normally closed contacts of the positive and reverse contractors were also connected in series with each other in the control loop, thus playing a double linkage between the button and the contactor.

The control principle was shown in Fig.1. [4], when the forward start button SB1 of the motor M was pressed, the motor $\mathrm{M}$ starts counterclockwise and runs continuously. When the reverse start button SB2 of the motor $M$ was pressed, the motor $\mathrm{M}$ starts in the reverse direction and ran continuously. The normally closed contacts of button SB1, SB2, contactor KM1 and contactor KM2 were respectively connected in series in the coil loop of the other contactor. When contactor KM1 was energized, contactor KM2 could not be energized. Conversely, when contactor KM2 was electrically closed, contactor KM1 could not be electrically closed.

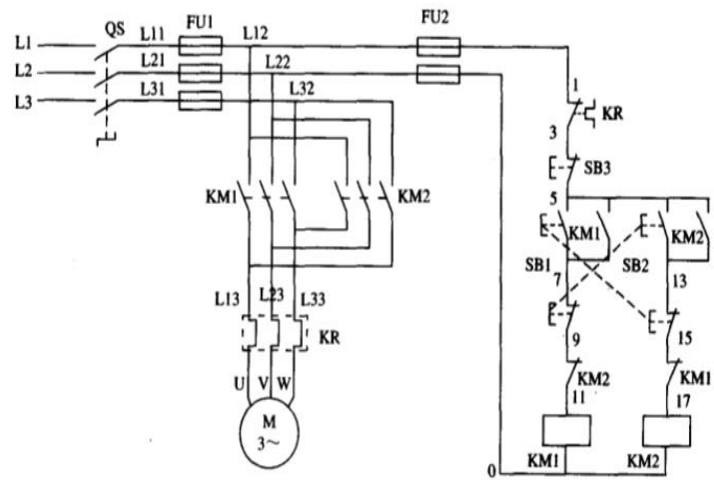

Fig.1. Control principle

\section{B. The component selection and simulation implementation with Yulong electromechanical control simulation software}

The melt current of the fuse was selected according to the motor. Given that the motor's rated current is $71.11 \mathrm{~A}$,

According to the formula, the melting current was 110A.

According to the principle of the circuit diagram, the selected component, in turn, had been arranged in sequence, connecting the wire, operating circuit simulation, such as could realize the above function. The implementation of simulation control was shown in Fig.2. 


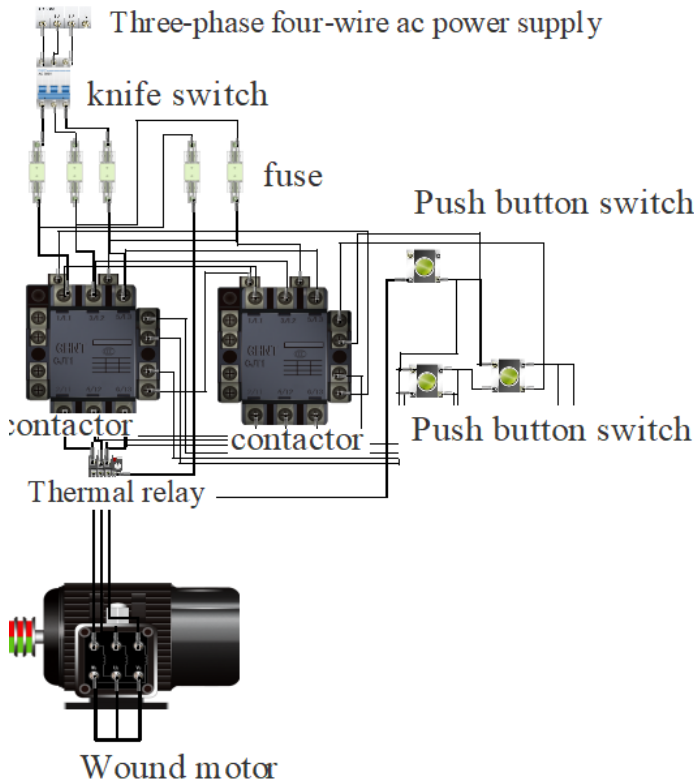

Fig.2. Simulation control implementation

\section{PLC control for three-phase asynchronous motor double interlock positive and negative rotation control circuit}

The control mode was changed to PLC control; the control circuit mainly considered the control circuit sequence and control form.

TABLE I. PLC INPUT/OUTPUT POINTS ALLOCATION

\begin{tabular}{|c|c|c|}
\hline \multicolumn{3}{|c|}{ Input signal } \\
\hline Name & Code name & Input code name \\
\hline Forward start button & SB1 & $\mathrm{I} 0.0$ \\
\hline Reverse start button & SB2 & I0.1 \\
\hline Stop button & SB3 & $\mathrm{I} 0.2$ \\
\hline Thermal relay & KR1 & $\mathrm{I} 0.3$ \\
\hline \multicolumn{3}{|c|}{ Output signal } \\
\hline Name & Code name & Output code name \\
\hline Forward contactor & KM1 & Q0.0 \\
\hline Reverse contactor & KM2 & Q0.1 \\
\hline
\end{tabular}

According to the characteristics of the above control circuit list of PLC input/output point allocation table, see TABLE I.

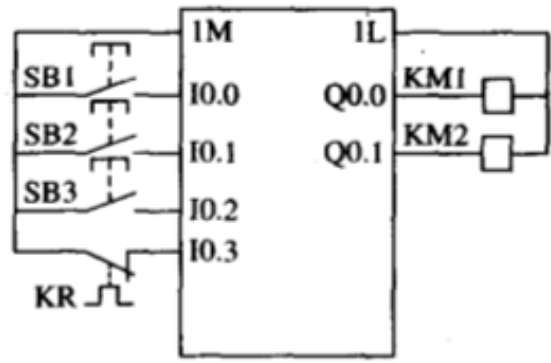

Fig.3. PLC control wiring diagram

Control circuit PLC control wiring diagram was shown in Fig.3.The programming idea was as follows:

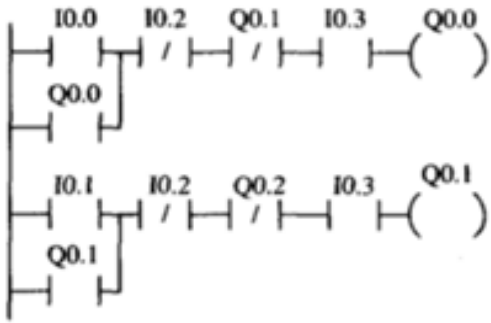

Fig.4. PLC control ladder diagram

- When the button SB1 (I0.0) was pressed, Q0.0 received electricity and self-locks, and the motor $M$ turned forward.

- When the button SB2 (I0.1) was pressed, Q0.1 gained power and self-locks, and the motor $\mathrm{M}$ reversed.

- Q0.0 and Q0.1 interlocking.

Control circuit PLC controlled ladder diagram was shown in Fig.4. According to the wiring diagram, connecting wire,

checking the order of all wiring, editing and importing the

PLC program, and then simulated circuit running. If the circuit ran normally, click on the button. Such could realize the simulation control based on PLC. The implementation of simulation control was shown in Fig.5.

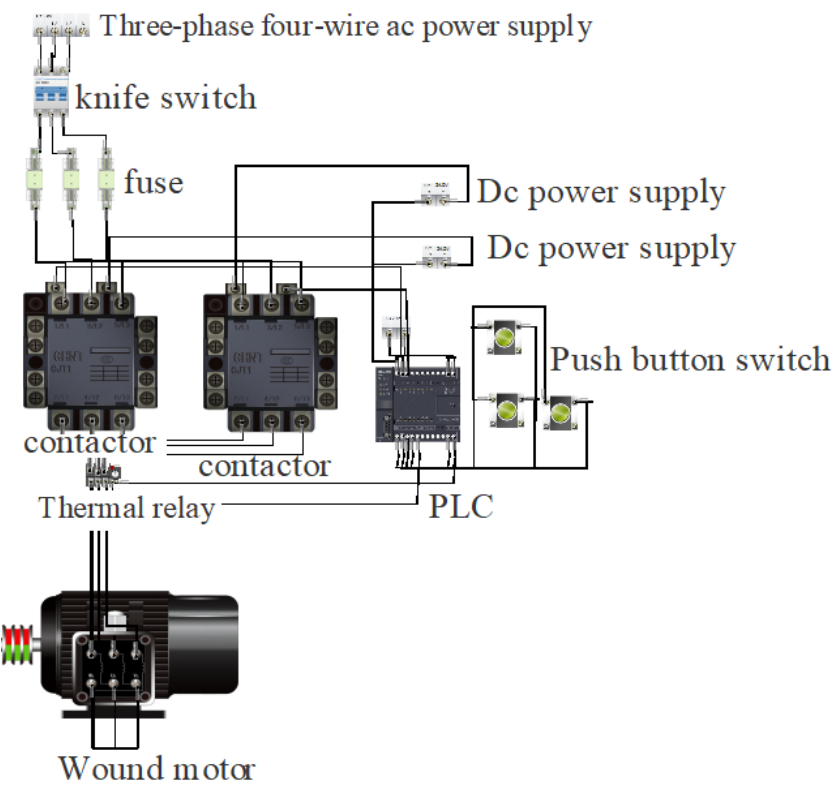

Fig.5. PLC simulation implementation

\section{MicRO-COURSE OF INNOVATIVE STAR OBSTACLE AVOIDANCE CAR PROJECT}

Before the obstacle avoidance car experiment project, the micro-class related to the creative star was released to the students in advance. Such, the students could use the fragmented time to preview, and then carried out the 
implementation of the project in the laboratory. It could significantly improve experimental efficiency, inspired students to develop innovative learning ideas, and always maintained the enthusiasm of learning new knowledge.

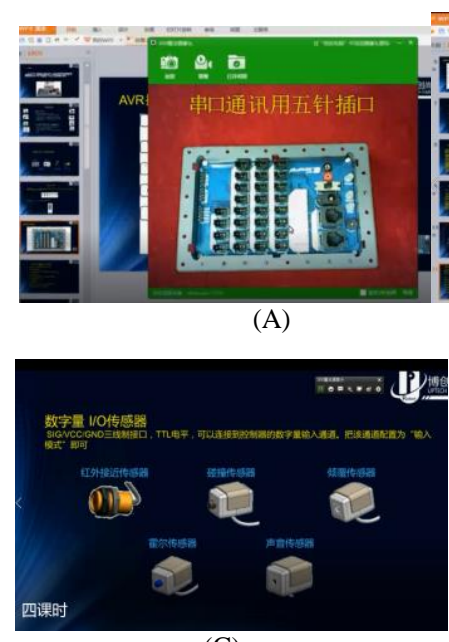

(C)

(E)

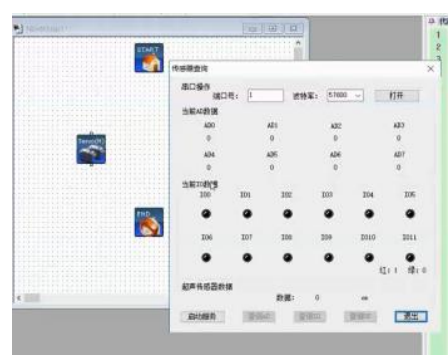

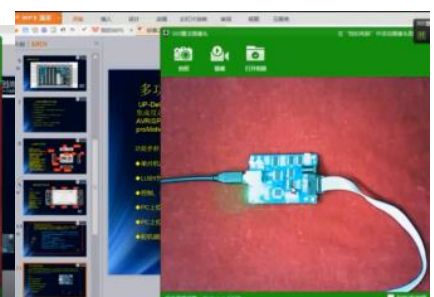

(B)

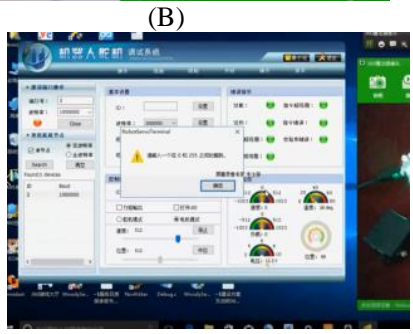

(D)

(F)

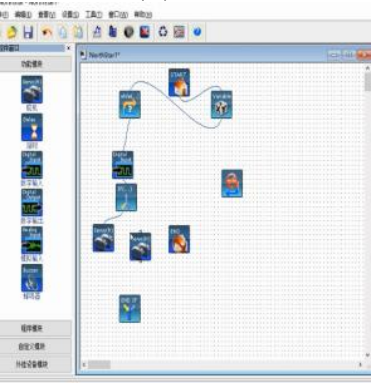

Fig.6. The micro-course of innovative star

The pre-planned micro-lectures included: (A) introduction of the controller; $(B)$ introduction of multifunctional modules; (C) introduction of sensors; (D) usage of steering gear; (E) online query of sensors; (F) NORTHSTAR software programming demonstration; See Fig.6.

The obstacle avoidance car experiment project mainly used the infrared sensor to realize the obstacle avoidance function.

When the obstacle in front of the robot was less than the infrared sensor, the output value of the infrared sensor would become $0.10 \mathrm{cmBy}$ writing a program to continuously query the state of the IO port connected to the infrared sensor, the distance state of the robot from the obstacle could be known.

The algorithm of car obstacle avoidance was as follows:

- If there was no obstacle in front $(\mathrm{IO} 0=1 ; \mathrm{IO} 1=1)$, the robot moved forward (left motor gave positive speed, right motor gave negative speed).

- If there was an obstacle on the left ( $\mathrm{IO} 0=0 ; \mathrm{IO} 1=1)$, the robot turned left (left motor gave negative speed, right motor gave negative speed).
- If there was an obstacle on the right $(\mathrm{IO} 0=1$; $\mathrm{IO} 1=0)$, the robot turned left (left motor gave positive speed, right motor gave positive speed).

- Other cases (IO0 =0; IO1 = 0), the robot turned left (left motor gave positive speed, right motor gave positive speed).

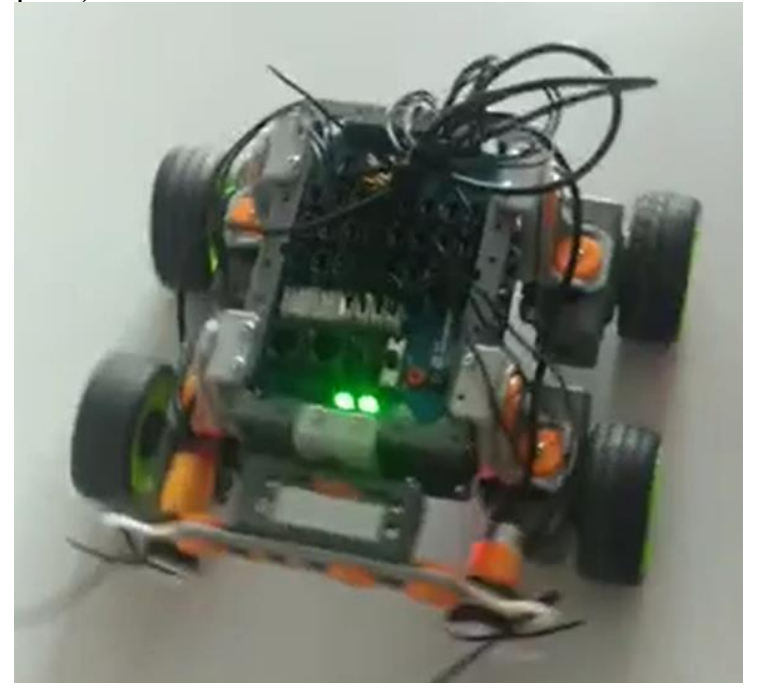

Fig.7. Construction and realization of obstacle avoidance car

According to the above algorithm, the obstacle avoidance car based on the standard version of the creative star was shown in Fig.7. Due to the base of previewing the previous micro-class, the experiment was very successful and greatly improved students' interest in learning comprehensive courses such as an electromechanical comprehensive experiment.

\section{REFORMING THE EVALUATION WITH RECORDING} SCREEN AND REMOTE CONTROL

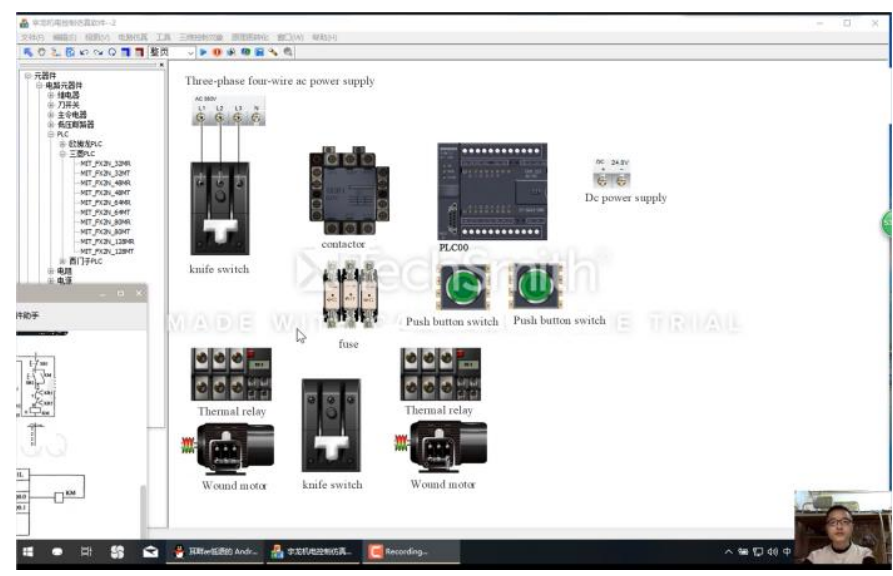

C620 type general lathe simulation control screen examination

Fig.8. Student's screen recording

New evaluation methods added the recording screen of simulation experiment (as shown in Fig.8.), remote network demonstration, defense, and on-site PK of experiments among students except for the traditional experimental evaluation, such as operation process, operation habits; experimental report 


\section{REFERENCES} enthusiasm for active learning. And the effect in practice was far better than the traditional teaching evaluation model.

\section{SUMMARY}

The usage of electromechanical control software decreased experiment cost. Micro-course increased the efficiency of the experiment and reduced the student's time on knowledge learning. The new evaluation method of recording the screen and remoting demonstration inspired the student's positivity on the electromechanical experimental course. In a word, the electromechanical experiment has become the most favorite course in college after this new teaching design.
[1] Guo Longchuan, "Application of simulation teaching design in electromechanical transmission and control course," Education modernization. China, vol.14. pp. 157-159, July 2018.

[2] Cao Lishuo, Liu Yiming et al. "PLC control of stepping motor by Yulong simulation software," Electronic world. China, vol.24. pp.196197, December 2017.

[3] Zhang Wenfeng, "Research on the application of virtual simulation technology in mechanical engineering experiment teaching," Internal Combustion Engine \& Parts. China, vol.19. pp. 247-248, October 2019.

[4] Yang Na, "Application of Yulong simulation software in electrical control experiment teaching," Journal of Taiyuan Urban Vocational College. China, vol.5. pp. 38-39, May 2014. 